\title{
ESPACIO VIVIDO: DEL ESPACIO LOCAL AL RETICULAR. NOTAS EN TORNO A LA REPRESENTACIÓN SOCIAL DEL ESPACIO VIVIDO EN LA GLOBALIZACIÓN
}

\author{
Enriqueta Lerma Rodríguez \\ CIESAS-Sureste \\ Investigadora de estancia posdoctoral \\ enriquetal@yahoo.com.mx
}

\section{RESUMEN}

En este artículo argumento la necesidad de repensar el espacio vivido. Propongo complejizar el análisis, consensado teóricamente, del espacio local, integrando el enfoque del espacio reticular. Busco incluir el margen de espacialidad que los grupos sociales construyen fuera de sus lugares cotidianos para explicar las representaciones sociales del espacio vivido, producto de las posibilidades de movilidad social hacia otros lugares.

Palabras clave: espacio vivido, espacio local, espacio reticular, movilidad social, representaciones sociales.

\section{LIVED SPACED: FROM LOCAL TO RETICULAR SPACE. NOTES ON THE SOCIAL REPRESENTATION OF LIVED SPACE WITHIN GLOBALIZATION}

\begin{abstract}
In this article, I defend the need to rethink lived space. I propose increasing the complexity of the analysis of local space, based on theoretical consensus, by integrating a reticular approach to space. I seek to include the margin of spatiality that social groups construct outside their every day places in order to thus explain the social representations of lived space resulting from the possibilities of social mobility toward other places.
\end{abstract}

Key words: lived space, local space, reticular space, social mobility, social representations. 


\section{INTRODUCCIÓN}

Este artículo buscar dar continuidad a la discusión sobre el estudio del espacio vivido, misma que se ha generado a partir de las reflexiones de Paul Ricouer (Gómez 2001), Merleau-Ponty (Riera 210), Ernest Cassirer (Ortega 2000), Yi Fu Tuan (2007), entre otros. Dicho enfoque se centra en analizar la forma en que la gente conoce, percibe, significa, se apropia y reproduce, su propio espacio. Al debate han contribuido geógrafos, filósofos, sicólogos, y urbanistas, quienes desde sus disciplinas han profundizado en diferentes aspectos: el espacio físico, la existencialidad, la semiótica del espacio y los usos ideológicos de la arquitectura. Sin embargo, la trascendencia de la movilidad social y su efecto en las representaciones sociales del espacio cotidiano es algo que falta integrar al tema. Se ha mantenido una noción implícitamente estática y cerrada de los lugares, pues no se toma en cuenta la importancia que cobran las redes físicas y simbólicas que relacionan a una localidad con otras, ni considera la movilidad de las personas como factor que trasforma las representaciones sociales del espacio. En este artículo propongo incluir en el análisis del espacio vivido procesos que permiten entender a las localidades como instancias que forman parte de un espacio complejo, interrelacionado y en trasformación; procesos tales como la migración, las diásporas, el exilio, las territorializaciones y las ocupaciones de tierras, mismos que trasforman la conceptualización del espacio local y la manera en que las personas se relacionan con su entorno inmediato. Para exponer estas ideas en primera instancia hago una rápida revisión de cómo ha sido estudiado el espacio vivido, después me centro en mi aporte a la discusión: explicar por qué el espacio vivido involucra lugares que están más allá de la localidad y por qué la movilidad social complejiza las representaciones sociales del espacio cotidiano.

\section{LOS FUNDAMENTOS DEL ESPACIO VIVIDO}

Los estudios acerca del espacio vivido se interesan por la relación directa entre las personas y su espacio próximo. Por ello incluye trabajos en diferentes niveles, desde la construcción cultural de la proxémica (Hall 2002), hasta aquellos que abordan el espacio vivido a una escala regional (Barabas 2003). El objetivo de este enfoque es dar cuenta de cómo la gente, 
fuera de la teorización, vive el espacio con el cuerpo, cómo lo siente, lo nombra, lo significa, se lo apropia. Como señala Gualteros (2006), en el estudio del espacio vivido se toma en cuenta cómo «la gente reconoce y significa». Lo que supone la creación de espacios a través de los cuales las personas despliegan sus intereses, sus pasiones y sus deseos. Sánchez (1991: 214) también lo define como espacio de convivencia al ser la instancia en que se desarrollan las interacciones sociales diarias; se centra en las coordenadas del aquí y del ahora, con base en las relaciones que hombres y mujeres mantienen con su espacio inmediato.

Algunos antecedentes se encuentran en los trabajos pioneros de Henry Lefebvre (Lindón 2004), quien sin hablar aún de espacio vivido, lo aborda en su análisis de la vida cotidiana. El autor lo concibe como una producción, resultado de aspectos objetivos y subjetivos, generados por los actores sociales en su vida diaria y en relación con la historia. Alicia Lindón (2004: 42) señala al respecto:

Es importante destacar que el espacio de la vida que nos presenta el autor es el de las prácticas de los actores, está cargado de significados y también es delimitado. En este espacio se incorpora la idea de «límite» como una forma de recortar no sólo desplazamientos cotidianos de los actores, sino también ámbitos de significación asociados a la experiencia que los actores tienen de diferentes porciones del espacio. Esta forma de espacialidad de la vida cotidiana es muy cercana a lo que las geografías existencialistas y el humanismo geográfico, desde los años setenta, estudian a partir del concepto de «lugar» o bien el de «espacio de vida».

Para Lefebvre es importante observar la pluralidad de sentidos y de significados que guarda un mismo lugar para diferentes actores. Asimismo propone el concepto de espacios de representación para señalar las formas de conocimientos locales, opuestas a las ideologías dominantes del espacio. Estos espacios se conciben con menos formalidad, son dinámicos, simbolizados por sus habitantes y sus significados se construyen y modifican en el trascurso del tiempo por los actores sociales. «Se desarrollan constantemente en una 
relación dialéctica con las representaciones dominantes del espacio que intervienen, penetran y tienden a colonizar el mundo-vida del espacio de representación» (Lan y Migueltorena 2011: 112). El autor concibe que el espacio de representación, aunque es sujeto de dominación, es también fuente de resistencia.

En los aspectos señalados el interés de Lefebvre coincide con la geografía humanística, donde propiamente se originaron los estudios acerca del espacio vivido (Estébanez 1982, Gómez 2006). Dicha tendencia tomó distancia del método usado en las escuelas previas -incluyendo la propuesta marxista de Lefebvre - que partía de grandes marcos teóricos de referencia. Pasó del método deductivo al inductivo, dando predominio a la mirada fenomenológica, caracterizada por rescatar las nociones del sentido común, llamadas también conceptualizaciones de primer grado construidas en la vida cotidiana (Berger y Luckmann 2006). Con esta propuesta cobró importancia la manera en que los habitantes nombran su localidad y sus lugares, trazan y recorren los caminos, describen sus paisajes, institucionalizan sus espacios, por lo que fue necesario tomar en cuenta los lugares de residencia, las vivencias, los recuerdos, las ocupaciones, así como las actitudes negativas o positivas sobre los sitios cotidianos.

No son vastos los trabajos con este enfoque, por lo mismo los interesados recurren generalmente a una misma raíz teórica que permite abordar la subjetividad individual o grupal y su relación con el medio. A Merleau Ponty se le adjudica el haber sentado las bases del espacio vivido, ya que destacó la experiencia como fundamento del conocimiento y la conformación de la internalidad y la externalidad humanas, mismas que moldean nuestra percepción. (Gómez 2001). Con base en estos principios se sentaron las bases para afirmar que el espacio no es percibido nunca del mismo modo por dos individuos y cuenta con múltiples significaciones en distintas culturas: «No hay dos personas que perciban de forma precisamente igual la misma realidad ni dos grupos que hagan exactamente igual la valoración de su medio» (Tuan 2007: 15). La geografía se benefició con esta visión al 
romper la dicotomía entre espacio universal y personal; dio preponderancia a la escala local o regional, que permite analizar la experiencia cultural del espacio.

Alicia Lindón y Daniel Hiernaux señalan que el concepto de espacio vivido fue propuesto por Armand Frémont en 1974 y definido por Jaques Chevalier en el mismo año de la siguiente manera:

La propuesta del espacio vivido no se limita a reconocer lugares frecuentados, definir itinerarios, situar al hombre-habitante en su lugar en su cuadro familiar de existencia [...] sino focalizar la mirada en la relación con las representaciones [...] es decir superar el espacio extensión (o espacio-soporte) para abordar la noción de representación (imagen) del espacio, planteando una nueva pregunta: ¿cómo ven los hombres el espacio? (Chevalier, en Lindón y Hiernaux 2006: 382).

Yi Fu Tuan contribuyó de manera significativa al señalar varios aspectos involucrados en la conceptualización social del espacio vivido: la importancia de la percepción sensorial, la influencia de las actitudes, el papel de la cultura y el peso de los valores. Con Tuan la geografía inauguró un nuevo campo de estudio, más cercano a la antropología y con una mirada acotada hacia lo local. Tuan argumentó que el etnocetrismo espacial - ponerse uno mismo, su país o su planeta en el centro del universo- «es un atributo humano genérico» (2007: 50). En ese sentido la representación social del espacio para cada cultura es concéntrica, una mirada que se construye desde el lugar propio y que mira hacía otros más lejanos: la región, la frontera, la otredad. Del «aquí» a lo que «ya no conozco» y que por su distancia no alude más a mi sensibilidad. Por eso Tuan denomina como topofilia a la relación que hay entre los sentimientos y el lugar de pertenencia. La delimitación analítica del espacio vivido, por tanto, es restringida; una idea compartida por Anne Buttimer y E. C. Relph, geógrafos humanísticos, para quienes es importante destacar el vínculo que une al hombre y al lugar, «estos lazos se consideran que, cuando son sólidos y afectivos, confieren una cierta estabilidad al individuo y al grupo» (Estébanez 1982: 23). 
El estudio del espacio vivido puede puntualizarse de la siguiente manera:

- Se origina en la geografía humanística.

- Usa el método fenomenológico, por tanto, es descriptivo y deductivo.

- Se interesa en encontrar las relaciones entre el espacio, la percepción, los lugares de la cotidianidad y sus representaciones.

- Da preferencia a la escala local sobre otras.

- Lo más importante es el punto de vista que los habitantes construyen a nivel social sobre su lugar propio.

Además de estos principios, no está de más señalar su distinción con el «espacio de vida», que aunque relacionado, se centra en otros aspectos: «Para Di Meo el espacio de vida se confunde, para cada individuo, con área de sus prácticas espaciales. Es el espacio frecuentado por cada uno de nosotros, con sus lugares atractivos, sus nodos en torno a los cuales se construye la existencia individual: la morada, la casa, los lugares de trabajo de y ocio» (Lindón y Hiernaux 2006: 382).

\section{INTEGRANDO LA CULTURA AL ANÁLISIS DEL ESPACIO VIVIDO}

Algunos historiadores y antropólogos consideran que el estudio del espacio vivido debe abordarse a escala regional y no local (Viqueria 1994, Barabas 2003). La Geografía Cultural prefirió como instancia espacial de análisis el paisaje (Claval 1999). Esta escuela también renunció a la conformación de grandes teorías generales para interesarse por temáticas más específicas y tratar de comprender las particularidades culturales impresas en el espacio. Coincide con los estudios del espacio vivido en su interés por interpretar la relación directa hombre-medio: «Ahora se sistematiza el estudio de una persona que pertenece a un pequeño grupo de un barrio marginal en una ciudad y se aspira, a lo más, a verificar la manera en que esta persona, y las que le son culturalmente afines, producen sus paisajes, o producen sus espacios» (Fernández Christlieb 2006: 227). Como parte de su método de observación la Geografía Cultural señala que al analizar un paisaje se debe 
poner acento en cinco aspectos: la forma en que sus habitantes reconocen el lugar; la manera como se orientan; las marcas territoriales que indican — mojoneras, intersecciones, caminos, límites, etcétera-; en cómo se nombran los lugares, así como en las explicaciones que sustentan dicha toponimia; y las formas institucionalizadas de los lugares significativos (Fernández Christlieb 2006: 232). No obstante, el interés exclusivo de la geografía cultural por las representaciones de los grupos subalternos contrasta con el estudio del espacio vivido que también se interesa por las representaciones de las clases dominantes (López 2006).

No puede decirse que los estudios sociológicos y antropológicos han estado al margen de esta discusión. Por distintas vertientes la relación espacio-sociedad ha sido abordada. Entre los temas tradicionales de la antropología — cosmovisión, organización social, identidad, parentesco, etcétera - se incluyen definiciones, descripción y análisis de territorios, localidades o lugares, aun así no se les ha identificado como resultado de un enfoque interesado en el espacio vivido. Entre las propuestas antropológicas destaca el concepto de «lugar antropológico» de Marc Augé (2000); definido como un espacio construido por los antepasados, marcado de signos posibles de ser leídos por quienes viven esa cultura, inscrito de historia, compuesto por itinerarios, intersecciones, centros y monumentos; es simbolizado, puede ser recorrido y se sostiene por discursos y por lenguajes específicos. Sin embargo, Augé señala la proliferación cada vez más exhaustiva de «no lugares»: espacios carentes de identidad, generados en la sobremodernidad y que han ganado terreno en la sociedad actual. No coincido del todo con esta idea, pues asumo que los espacios calificados como «no lugares»: aeropuertos, caminos, supermercados, etcétera, son resignificados en diferentes culturas, asimismo las relaciones sociales que se producen en su interior son siempre diferentes, están cargadas de significado y cuentan con valoraciones individuales.

En la antropología mexicana, por su parte, se han comenzado a generar estudios interesados en la forma como las personas representan su propio espacio a una escala regional. Una de 
estas propuestas es la del análisis del etnoterritorio, cuyo objeto de estudio son las formas simbólicas en que los pueblos indios actuales construyen territorialidad (Barabas 2003: 15). Dicho enfoque comparte con el espacio vivido el interés por explicar la manera en que los grupos significan, reconocen y habitan el espacio que identifican como propio. Aun así la fractura entre ambas perspectivas es considerable, pues mientras el espacio vivido aboga por rescatar las conceptualizaciones de la vida cotidiana, el análisis etnoterritorial «supone cierto nivel de abstracción, ya que no se trata de territorios de lo cotidiano» (Barabas 2003: 22). De este modo mientras el espacio vivido usa como herramienta la fenomenología, que le conduce al estudio del «aquí» y del «ahora», el etnoterritorio buscaría las permanencias del núcleo duro (López Austin 2001: 147-165) ${ }^{1}$ que permiten la continuidad de las significaciones culturales de un grupo sobre el espacio.

Encuentro los estudios etnoterritoriales muy cercanos a la geografía cultural, sólo que los primeros omiten el paisaje como escala de análisis y en su lugar toman como referencia lo que señalan como territorio cultural: el «ocupado por los grupos entolingüísticos que lo habitan y que mantienen una relación histórica con él» (Barabas 2003: 23). Aun así, ambas escuelas coinciden en retomar la cosmovisión de los grupos nativos, la forma de nombrar, apropiarse e institucionalizar los lugares, de dotarlos de singularidad e historia, pero se distinguen en cuanto a la instancia espacial que analizan: región cultural y paisaje, respectivamente.

Como se observa, el etnoterritorio, la geografía cultural y el espacio vivido confluyen en las representaciones sociales del espacio en una escala humana. Otro aspecto en común es el predominio de una visión concéntrica del espacio.

Otros estudios hechos desde la antropología mexicana son los realizados y compilados por Ana María Portal (2011a; 2001b), quien se ha interesado por analizar las representaciones sociales de algunas localidades urbanas en México. 


\section{FORMAS EN QUE SE HA INTERPRETADO EL ESPACIO VIVIDO}

Yi Fu Tuan considera que los seres humanos poseemos otros modos de percibir el mundo, éstos no se limitan a nuestros cinco sentidos: vista, oído, olfato, gusto, tacto. «La dimensión de los objetos percibidos varía enormemente de una cultura a otra, pero esas dimensiones se sitúan dentro de un rango dado» (2007: 29). Para interpretar el modo en que cada cultura comprende el espacio Tuan propone analizar aspectos comunes en todas las sociedades: las formas de segmentación; las oposiciones binarias; los elementos básicos que componen los objetos; los esquemas cosmológicos y su significado; la sicología del color y la sicología espacial; así como la propensión a ordenar el mundo desde el etnocentrismo (2007: 27-67).

Por otro lado, invita, entre muchos otros aspectos, a observar las siguientes distinciones culturales: la construcción de la individualidad y de los mundos personales; las particularidades de la percepción por rango de edad y por género; las actitudes hacia el entorno geográfico a partir de la cosmovisión; la clasificación cultural entre entornos naturales y arquitectónicos; las modalidades de respuesta al entorno de los seres humanos, desde la apreciación visual y estética hasta el contacto físico; las relaciones entre topofilia y factores como salud, parentesco y conciencia del pasado; el impacto de la urbanización en la apreciación del campo y de las tierras vírgenes; entre muchos otros. Con estos indicadores Tuan realizó un trabajo exhaustivo, capaz de marcar directrices para nuevos trabajos.

Una de las metodologías más recurrentes para conocer las representaciones sociales del espacio vivido ha sido a través del análisis de mapas mentales, elaborados por informantes. Fue difundida, desde la arquitectura, por Kevin Lynch en su obra La imagen de la Ciudad (1959). El autor propone observar qué objetos son identificados por los participantes, cómo los relacionan entre sí en una idea estructurada y qué significado se les atribuye. Plantea también poner atención en la recurrencia de algunos elementos: sendas - calles, caminos, vías, senderos, canales—, bordes — límites, rupturas de continuidad, muros-, barrios $-\mathrm{o}$ distritos-, nodos — cruces, confluencias, intersecciones - y mojones —elementos que 
sobresalen, tales como tiendas, iglesias, monumentos, etcétera, que son representativos del lugar o que sirven de indicadores en el mapa- Con posterioridad, Lynch y su equipo de trabajo hicieron entrevistas a los informantes, a los que acompañaron en recorridos por la ciudad para escuchar sus puntos de vista acerca de los lugares que les fueran significativos. La investigación de Lynch dejó marcada influencia, tal como señala Martha de Alba (2010); pero también recibió críticas por el acento que puso en el espacio físico y la infraestructura.

Desde la sicología social sobresale el trabajo de Stanley Milgram y Denise Jodelet: Las representaciones sociales de París. Aquí los autores ofrecen un análisis de mapas mentales con base en la propuesta de las representaciones sociales de Serge Moscovici. Martha de Alba (2010) explica que un primer paso en la aplicación de esta teoría es identificar el objeto de representación y los individuos o grupos que construyen las representaciones de ese objeto (2010: 6). Más tarde se analiza lo que Moscovici identificaría como mecanismos de pensamiento: la objetivación y el anclaje. El primero convierte una representación abstracta en algo concreto, permitiendo a los individuos y grupos expresar ideas o imágenes que toman forma y cuerpo a través del lenguaje, de prácticas o de esquemas comunicables socialmente. El segundo «asimila un objeto nuevo de representación a algo ya conocido, lo que nos permite comprenderlo e incorporarlo a nuestra realidad cotidiana». En el anclaje la memoria social es importante, dado que activa el bagaje sociocultural para la representación de un nuevo objeto (2010: 6-7). Alba explica que este marco teórico, llevado al campo de las representaciones sociales del espacio, permite comprender los significados de los lugares, en función de la identidad de los sujetos sociales. Con base en un espacio delimitado y la selección de un grupo específico, «los objetos de representación socioespacial pueden relacionarse con la memoria social al seleccionar lugares que tienen un significado especial o trágico debido a los sucesos que ocurrieron en ellos. Por ejemplo, podemos estudiar las representaciones de los espacios de represión política, aquéllos que fueron escenario de guerras, revoluciones, o de actos de poder» (2010: 8). La teoría de Moscovici, aunada a la investigación de Milgram y Jodelet, inspiraron trabajos posteriores 
(Alba 2004a, 2006, 2010; Arruda y Alba 2007; Giménez 2007; Palacios 2010), en éstos el énfasis se coloca en la subjetividad social por encima de la estructura física de los espacios.

Otro procedimiento es el método ALCESTE (Análisis Lexical de Coocurrencias de Enunciados Simples de un Texto), que profundiza, de manera estadística, en ciertos indicadores recurrentes y en elementos dominantes del contexto, plasmados en los mapas mentales (Alba 2004b).

El espacio vivido también ha sido analizado con base en la teoría de los imaginarios sociales, inaugurada por Cornelius Castoriadis, filósofo que señala la imposibilidad de separar el imaginario y la realidad en los objetos sociales. La realidad es siempre indeterminada, prestándose así a la plasticidad, al dinamismo y a la trasformación (Tello 2003). Sin embargo, cuando es instituida, se establece como discurso y orden natural de la sociedad, muchas veces sustentado más en imaginarios que en funciones reales. La contradicción se muestra en las prácticas que realizan los actores sociales al margen del poder, a las que Castoriadis llama instituyentes. El objetivo de esta perspectiva ha sido conocer cómo se ha construido la «realidad» institucionalizada y a partir de qué mecanismos (Pintos 2000, Baeza 2003), y trata de desentrañar las partes que conforman la «realidad», analizando los imaginarios que subyacen a cada objeto. Amalia Campos (2010) relaciona los imaginarios sociales y el espacio del siguiente modo:

Los imaginarios sociales refieren también a la apropiación simbólica del espacio, es decir, se construyen por las interacciones entre los sujetos y el colectivo en un territorio. De manera que el grupo construye y valida redes de significados imbricadas en el espacio y constituye «geosímbolos», a través de los cuales el individuo se adscribe como miembro de un colectivo, ya que corresponden a un contexto socio-cultural específico y refieren a la forma colectiva de concebir las realidades y sentires sociales (2010: 47). 
Bajo este enfoque destaca el trabajo de Daniel Hiernaux, quien ha realizado investigación sobre localidades urbanas y centros turísticos en la posmodernidad (2006a, 2006b, 2009a, 2009b).

\section{ESPACIO CONCÉNTRICO Y ESPACIO RETICULAR}

Aun sin proponérselo el estudio del espacio vivido implica una noción estática y concéntrica. Se considera cómo se relacionan las personas con su medio próximo, centro deíctico del mundo, pero no integra la influencia de otros lugares en la conformación de la localidad. Por tratarse de la percepción del espacio a escala humana se deduce que el lugar por analizar comprende únicamente las percepciones construidas en la espacialidad que se abarca en la vida cotidiana. Dicha idea, que no es ajena en otros estudios, considera que las relaciones socioespaciales parten de un lugar propio - el centro- hacia la periferia. Por tanto la manera como se aborda el espacio es definiendo por escalas que van en dirección concéntrica ascendente: lugar, localidad, región, territorio nacional, región continental, mundo. Sin embargo, ninguna sociedad es cerrada ni estática: todas se encuentran en contacto y en constante circulación con otras de manera diferenciada. La movilidad de sus miembros no se presenta con la misma importancia de un centro hacia distintos puntos de una misma circunferencia, ni con la misma intensidad hacia diferentes direcciones, así que el espacio no se experimenta concéntricamente. Se produce con fuerte influencia de lugares cercanos, pero ésta no necesariamente se desvanece con la lejanía. El espacio se produce con la movilidad y el contacto social con lugares colindantes y discontinuos. No hablo de regiones nodales, pues éstas se caracterizan por un lugar central en rededor del cual se organizan otras regiones o localidades (Haggett 1976: 27).

El espacio vivido ciertamente debe tomar en cuenta como principio el análisis del espacio local, pero en el contexto actual de globalización y con flujos de migración constante, éste sólo es comprensible en relación con un espacio reticular. Es a través de rutas, caminos, medios de comunicación y migraciones que los lugares se encuentran relacionados. No necesariamente es a escala humana, local y caminable. Hay circulación de personas y de 
objetos que a pesar de estar en lugares alejados y muchas veces trasnacionales forman parte de una misma red que permite la proximidad social entre los espacios (López 2005). Como señalara Luis Cayón en el caso de los yanomami, su espacio está «constituido por un complejo de caminos y conexiones entre diferentes sitios o puntos, los cuales están marcados por toponimias, y líneas o rutas», su conocimiento etnogeográfico «se sustenta en una rica toponimia compuesta por un conjunto de sitios relacionados por una compleja red de caminos interconectados» (2008: 144). Pensar el espacio de esta manera permite entender las representaciones del espacio vivido no solo en el lugar próximo sino en relación con otros lugares espacializados por un grupo social.

Pienso, por ejemplo, en el caso de los inmigrantes guatemaltecos asentados en el ejido La Gloria, ubicado en el municipio de La Trinitaria, Chiapas. Se trata de una comunidad indígena cuyos miembros mayoritariamente migraron a México en la década de 1980, huyendo de la guerra en Guatemala. Aunque de inicio pretendieron volver a su país, un gran número permaneció buscando la nacionalidad mexicana. Actualmente, igual que otros ex refugiados, han sido naturalizados como mexicanos. Los habitantes de La Gloria, quienes hoy en día se asumen como acatecos, han comenzado a desterritorializar su comunidad actual debido a una fuerte migración hacia Estados Unidos. Migración provocada por la crisis económica, la falta de acceso a la tierra, relaciones asimétricas negativas como ciudadanos mexicanos, carencia de empleo y ausencia de reconocimiento como grupo étnico nacional.

En una prueba piloto que apliqué a los jóvenes estudiantes de secundaria y bachillerato de esta comunidad encontré que más de $90 \%$ considera que vivirá fuera de su localidad en un periodo de diez años. Ellos suponen que para entonces radicarán en Playa del Carmen, Quintana Roo o en Estados Unidos de Norte América, destinos en los que cuentan con redes sociales fuertes. De manera inversa la posibilidad de regresar a Guatemala, donde también cuentan con familia, es nula, ningún estudiante mostró interés por radicar en el país centroamericano y algunos manifestaron abiertamente que no irían ni de visita. Si se 
considera que los padres de un gran porcentaje de estos jóvenes ya radican en territorio estadounidense, y se asume que siguen llegando a La Gloria ciudadanos guatemaltecos con destino a país del norte, surge la siguiente pregunta: ¿Cómo podríamos interpretar esta variable en el caso de los estudiantes? Por ahora se me ocurre una hipótesis que trabajaré en estudios posteriores: Los jóvenes acatecos, estudiantes de secundaria y bachillerato del ejido La Gloria en el municipio de La Trinitaria, Chiapas, representan su espacio vivido como un lugar de liminaridad, transitorio y de flujos, como un nodo más del espacio reticular que comprende la movilidad unidireccional Guatemala-México-Estados Unidos. ¿Y cómo se vive la cotidianidad en un espacio así? Con estas reflexiones, quiero mostrar que el análisis del espacio vivido debe abarcar no solo la historia del espacio local, sino también los procesos de trasformación del espacio in situ, generados por las posibilidades de movilidad que ofrece objetivamente el margen de espacialidad de un grupo. Dicha movilidad debe ser tomada como una variable significativa, pues ha sido internalizada por el grupo social que la pone en práctica.

Bajo este entendido el espacio vivido también debe tomar en cuenta el factor tiempo, ya que el espacio es representado de diversos modos en diferentes contextos sociohistóricos. Las actitudes positivas o negativas que puede mantener un grupo sobre su espacio actual pueden trasformarse al paso de los años como resultado de coyunturas que impliquen cambios drásticos. Hipotéticamente podría señalarse que las representaciones del espacio vivido construidas por los acatecos mexicanos han variado en diferentes etapas de su historia reciente. Los municipios mexicanos ubicados en la frontera con Guatemala de lado mexicano, en general, fueron representados durante el periodo de refugio como espacios de resguardo y en los que era necesario mantener el tejido social de la organización comunitaria para la subsistencia de sus miembros (Kauffer 1988). Pasada la etapa de refugio atravesaron por un periodo de conflictualidad, generada por la necesidad de ganar espacios propios, ya que se requería adquirir tierras propias para legalizar los asentamientos en un contexto de apatía por parte del gobierno mexicano para dotarlos de tierra (Ruiz 2007). Actualmente, como señalé arriba, siguiendo el caso de La Gloria, es posible que los 
asentamientos sean representados como espacios intermedios entre Guatemala y otros destinos.

\section{EL MARGEN DE ESPACIALIDAD EN LA REPRESENTACIÓN DEL ESPACIO VIVIDO}

Ahora bien, el espacio es reticular tomando en cuenta la espacialidad que domina un grupo, entendida ésta como la capacidad objetiva de desplazamiento sobre un determinado espacio: «La espacialización es movimiento concreto de las acciones y su reproducción en el espacio geográfico y en el territorio. La espacialización no es expansión, son flujos y reflujos de la multidimensionalidad de los espacios. Por lo tanto no existe la "desespacialización". Una vez realizada en movimiento, la espacialización se torna un hecho consumado, imposible de ser destruido» (Mançano 2006: 6).

Dado que ningún lugar es igual, y que todos se distinguen entre sí por ocupar distinta ubicación, las espacialidades de los diversos grupos se construyen por diferentes vías y con intersecciones en diferentes nodos espaciales, dependiendo de sus intereses, rutas y flujos migratorios. El resultado es la conformación de espacios reticulares diferentes.

No sobra decir que todo proceso de territorialización lo es también de espacialización, pero no a la inversa. La territorialización, como señala Mançano (2006, 2008), se interesa en el reconocimiento legal o legítimo sobre la posesión del espacio. La espacialización, en cambio, ya que hace referencia a la capacidad de desplazamiento, incluye las rutas de los flujos migratorios, las cuales, aunque pueden estar bajo el dominio de algunos grupos, no necesariamente buscan la oficialización. Un ejemplo de este fenómeno puede ser la ruta férrea que cruza el territorio mexicano, y que conecta la frontera sur México-Guatemala con la norte México-Estados Unidos, ruta usada de manera ilegal por migrantes indocumentados (Martínez 2011). El traslado se realiza en un tren llamado coloquialmente «La Bestia», el cual ha significado un serio y grave peligro para los centroamericanos que lo usan. La ruta se encuentra bajo el control de los maras - agrupaciones salvadoreñas- y otras organizaciones delictivas, quienes ejercen su dominio, sembrando muerte, pánico y 
desapariciones físicas entre los migrantes (Ultreras 2012). Sólo a través de un puntual conocimiento del recorrido, algunas veces vivido en carne propia y otras trasmitido en forma oral, algunos migrantes han podido sobrevivir y llegar a su destino. Visto desde los estudios tradicionales dicha ruta apenas podría ser catalogada como un «no lugar», sin embargo, la relevancia que ha cobrado en el imaginario migrante como medio para alcanzar «el sueño americano», y los discursos que ha generado para comunicar los peligros que implica su recorrido, han configurado fuertes representaciones sociales en su derredor y han promovido el establecimiento de una serie de instituciones que la acompañan.

El ejemplo de «La Bestia» muestra múltiples formas de vivir la espacialidad. Los migrantes han consolidado la espacialización de la ruta con el apoyo de organizaciones sociales que prestan albergue, orientación, seguridad, servicios médicos y que suministran alimentos. Las agrupaciones de ayuda, por su parte, ya producen en sí mismas otra forma de espacialidad, territorializándose a lo largo de la ruta férrea con infraestructura: cocinas comunitarias, casas de seguridad, albergues, centros de orientación, etcétera. Por otro lado se encuentra la espacialización de las agrupaciones delictivas y de las autoridades corruptas, quienes de manera informal o con acciones ilícitas mantienen el control sobre este espacio de flujos.

Pienso también en los efectos de otros procesos de espacialización como las diásporas étnicas forzadas. Una vez que se ha retornado o al momento de territorializarse los individuos han modificado la forma de construir su espacio y las representaciones sociales que mantenían sobre éste. Algunas de estas trasformaciones pueden leerse en los topónimos y en la forma de ordenar los asentamientos. Es el caso de la Tribu Yaqui, etina del noroeste mexicano que padeció el exterminio y el traslado forzado hacia otras regiones del sur del país a finales del siglo XIX y principios del XX. Al momento del retorno, en algunos pueblos yaquis como Pótam, los habitantes fundaron el Barrio Mérida y el Barrio Veracruz, indicando con esos nombres los lugares a los que habían sido consignados durante el 
destierro. En Pótam se adoptó el trazado de las calles cuadriculado, tipo urbano, dejando de lado el caserío disperso, forma original de los asentamientos yaquis (Spicer 1994: 340).

Otras formas de espacialización son a nivel micro o de lugar. Por ejemplo el 14 de enero de 2008 Telemadrid dio a conocer la noticia de que algunos trabajadores de limpieza hacían llegar a indocumentados instrucciones precisas de cómo salir del aeropuerto sin pasar por la aduana. El recorrido estaba milimétricamente descrito en hojas de papel, lo que mostraba espacialización precisa en el dominio de la ruta migratoria (2008). Esto es importante: el dominio de un grupo sobre una ruta hace posible la ampliación del margen de espacialidad, creando imaginarios y permitiendo arribar a nuevos lugares. Asimismo brinda certeza en las posibilidades reales de movilidad social hacia destinos cada vez más lejanos, conformando un espacio reticular cada vez más complejo.

Volviendo al caso de los guatemaltecos que solicitaron refugio a México en la década de 1980, destaco el caso de los kanjobales. Han sido comerciantes regionales desde tiempos ancestrales, su movilidad se ha caracterizado por ser constante, pero en los últimos treinta años han creado asentamientos en México y han migrado hacia Florida, Estados Unidos; actualmente viven también en Canadá y han ampliado su espacio reticular, a través de la solicitud de refugio, hasta continentes tan lejanos de Centroamérica como Australia (Aguayo 1987, Hernández 1988: 4).

El espacio vivido por tanto no se representa con una frontera del «aquí propio» y el «allá ajeno», es decir, permite incorporar el espacio discontinuo. A esto se suma el espacio de tránsito entre un lugar y otro. El camino es importante pues tiene sus propias dinámicas, normas, interacciones sociales, modos de uso y significaciones. Un análisis en sentido lo ofrece Neyra Alvarado (2008), para quien las peregrinaciones en el desierto noreste y noroeste mexicano no son únicamente un recorrido para trasladarse del lugar de residencia hasta el destino sagrado. Para la autora la peregrinación es necesaria pues permite el contacto con los ancestros. La ruta es tan importante como el lugar de llegada. De hecho 
cobra significación el arribo al lugar sagrado porque se ha librado con salud el laberinto que supone cruzar el desierto:

El laberinto es una noción que permite analizar el desierto, el espacio peregrino como una forma de comprender la circulación de las peregrinaciones. Esta noción hace posible identificar los diferentes caminos, las diferentes formas de organización religiosa, y cómo los peregrinos en su recorrido viajan hacia el lugar que los une a sus muertos, a sus ancestros. Hemos visto que en el caso pápago, la noción es acorde con diferentes formas de representación del espacio, ahora corresponde observar cómo la idea del laberinto y un lugar que une al peregrino con su pasado, con sus muertos y con sus ancestros, está presente en las peregrinaciones estudiadas (2008: 43).

La importancia del recorrido radica en que en este trayecto se construyen lealtades y lazos de solidaridad que posibilitan nuevas formas de organización social. En algunos casos, incluso, se forman nuevas identidades o se adecuan las previas para integrar nuevos elementos. Estas nuevas formas que se construyen en la experiencia del espacio reticular repercuten directamente en la reorganización del espacio vivido o en la expansión del margen de espacialidad.

Por otro lado es de tomar en cuenta que el espacio reticular, en específico el del camino, se vive de manera diferente dependiendo del sentido de la acción que motive su recorrido. En el caso que describe Alvarado, tiene un sentido numinoso, sin embargo, este mismo camino y recorrido puede ser usado por la misma comunidad como espacio de migración económica, dotándolo, por tanto, de otro significado.

\section{PARA CONCLUIR}

Los estudios del espacio vivido se inauguraron desde la geografía humanística, pero pueden enriquecerse si se incluye la perspectiva cultural de la antropología. La sugerencia es viable toda vez que ésta cuenta, como ya se mostró, con estudios similares, mismos que coinciden con muchos de los postulados del espacio vivido. 
El espacio vivido, analizado tradicionalmente en una escala local, sólo puede ser entendido en el contexto global. Sin embargo no todos los aspectos de la globalización inciden del mismo modo en todas las localidades, ni en la representación que las personas construyen de sus lugares propios. Cada localidad forma parte de una específica red de lugares que parecieran discontinuos, pero que están relacionados por caminos, rutas, flujos migratorios e intercambios materiales que la insertan en un espacio reticular. Siendo así es de considerar que el análisis de las representaciones sociales del espacio vivido tiene que ser analizado bajo esta perspectiva: como producto de la representación del espacio reticular y con base en el margen de movilidad de los grupos sociales, por lo que al espacio local puede ser considerado deícticamente como un lugar: «cercano de...», «lejano de...», «más pobre o más rico que...», «de refugio y seguridad», «de acumulación económica», «de retroceso», «de esperanza», etcétera.

El presente artículo es una invitación a continuar el diálogo en los temas que atañen al análisis del espacio vivido. Una de las críticas que se ha hecho a esta perspectiva es «que no implica ningún marco metodológico ni epistemológico explícito» (Staszak, en Lindón y Hiernaux 2006: 382), por ello, en cuanto a la metodología, se requiere trabajar con mayor profundidad, sobre todo si, como sugiero en estas páginas, se está de acuerdo en estudiar el espacio local en el contexto de la sociedad global.

\section{FUENTES DE CONSULTA}

Aguayo, Sergio, Hanne Christiensen, Laura O'Dogherty y Steffano Varesse, 1987, Los refugiados guatemaltecos en Campeche y Quintana Roo. Condiciones sociales y culturales, Instituto de Investigaciones de las Naciones Unidas para el Desarrollo Social/Colegio de México, México. 
Alba, Martha de, 2004a, «Mapas mentales de la Ciudad de México: una aproximación psicosocial al estudio de las representaciones espaciales», Estudios demográficos y urbanos, v. 19, n. 1, Centro de Estudios Demográficos y de Desarrollo Urbano, pp. 115143.

Alba, Martha de, 2004b, «El método ALCESTE y su aplicación al Estudio de las Representaciones Sociales del Espacio Urbano: El caso de la Ciudad de México», Papers of Social Representation. Textes sur les représentations sociales, v. 13. pp. 1.1-1.20.

Alba, Martha de, 2006, «Experiencia humana e imágenes colectivas de la Ciudad de México», Estudios demográficos y urbanos, Colmex, México, v. 21, n. 3, pp. 663-700.

Alba, Martha de , 2010, «Representaciones sociales y el estudio del territorio: aportaciones desde el campo de la Psicología Social», en Salomón González (coord.), La integración de la dimensión espacial en las ciencias sociales y humanidades: Un proyecto docente interdisciplinario, UAM-Cuajimalpa, México, en http://www.cua.uam.mx/csh/ebook/ [consulta: 26 de febrero de 2013].

Alvarado, Neyra, 2008, El laberinto de la fe. Peregrinaciones en el desierto mexicano, Colegio de San Luis, Consejo Nacional de Ciencia y Tecnología, México.

Arruda, Ángela y Martha de Alba, 2007, Espacios imaginarios y representaciones sociales, Anthropos, Universidad Autónoma Metropolitana-Unidad Iztapalapa, España.

Augé, Marc, 2000, Los no lugares. Espacios de anonimato. Una antropología de la sobremodernidad, Gedisa, Barcelona.

Baeza, Manuel, 2003, Imaginarios sociales. Apuntes para la discusión teórica y metodológica, Universidad de Concepción, Concepción, Chile. 
Barabas, Alicia, 2003, Diálogos con el territorio. Simbolización sobre el espacio en las Culturas Indígenas de México, Instituto Nacional de Antropología e Historia, Tomo I, México.

Berger, Peter y Thomas Luckmann, 2006, La construcción social de la realidad, Amorrortu, Argentina.

Campos, Amalia, 2010, «La línea... 'está ahí, es algo que se ve, pero que también se siente': imaginarios de frontera de las juventudes 'al sur'», Liminar. Estudios sociales y humanísticos, v. 3, n. 2. Cesmeca Unicach, México, pp. 46-70.

Cayón, Luis, 2008, «Idema: el camino de agua. Espacio, chamanismo y persona entre los makuna», Antípoda, n. 7, México, pp. 141-173.

Claval, Paul, 1999, «Los fundamentos actuales de la geografía cultural», Anales de Geografia, n. 34, Universidad Autónoma de Barcelona, España, pp. 25-40. http://ddd.uab.es/pub/dag/02121573n34p25.pdf [consulta: 3 de septiembre de 2012].

Estébanez, José, 1982, «Geografía humanística», Anales de geografía de la Universidad Complutense, n. 2., Universidad Complutense, España, en http://revistas.ucm.es/ghi/02119803/articulos/AGUC8282110011A.PDF [consulta: 10 de noviembre de 2011].

Fernández Christlieb, Federico, 2006, «Geografía Cultural», en Lindón, Alicia y Hiernaux, Daniel (Directores), Tratado de geografía humana, Anthropos, UAM-Iztapalapa, México, pp. 220-253. 
Giménez, Gilberto, 2007, «La frontera norte como representación y referente cultural de México», en Territorio y Frontera, año II, n. 3, México, pp. 17-34.

Gómez, Juan Carlos, 2001, «La experiencia cultural del espacio: el espacio vivido y el espacio abstracto. Una perspectiva ricoeureana», en Investigaciones geográfica, n. 44, México, pp. 119-125.

Gómez, Juan Carlos, 2010, «El espacio vivido, una geografía para la vida», en Contreras, Camilo y Narvaéz, Adolfo, La experiencia de la ciudad y el trabajo como espacios de vida, Plaza y Valdés, El Colegio de la Frontera Norte, México, pp. 15-28.

Gualteros, José, 2006, «Vida cotidiana y mundo urbano. Pautas para nuevas relaciones», en CLACSO, n. $\quad 16, \quad$ Argentina, en http://biblioteca.clacso.edu.ar/ar/libros/campus/poggiese/16truji.pdf [consulta: 29 de agosto de 2012].

Haggett, Peter, 1976, Análisis locacional en geografia humana, Gustavo Gili, Barcelona.

Hernández, Rosalva, 1988, «Mecanismos de reproducción social y cultural de los indígenas kanjobales refugiados en Chiapas», Tesis de Licenciatura en Antropología Social, Escuela Nacional de Antropología e Historia, México.

Hierneaux, Daniel, 2005, «Imaginarios y lugares en la reconquista de los centros históricos», Revista Ciudades, Red Nacional de Investigación Urbana, n. 65, México, pp. $15-21$.

Hierneaux, Daniel, 2006a, «Los centros históricos: ¿espacios posmodernos? (De choques de imaginarios y otros conflictos)», en Lindón, Alicia y otros (coords.), Lugares imaginarios en la metrópoli, Anthropos, UAM-I, México, pp. 27-41. 
Hierneaux, Daniel, 2006b, «Les imaginaires et les lieux dans la reconquête du centre historique de Mexico», en Rivière, Hélène y Memoli, Maurizio, Le pari urbain en Amérique latine. Vivre dans le centre des villes, Paris, Armand Colin, pp. 37-46.

Hierneaux, Daniel, 2009a, «Los imaginarios urbanos de la dominación y la resistencia: un punto de partida», Iztapalapa. Agua sobre lajas, UAM-Iztaplapa, México, pp. 7-12.

Hierneaux, Daniel, 2009b, «De los imaginarios a las prácticas urbanas: construyendo la ciudad de mañana», Iztapalapa. Agua sobre lajas, UAM-Iztaplapa, México, pp. 15-35.

Kauffer, Edith, 1988, «Los refugiados guatemaltecos en Chiapas y los derechos humanos. De la búsqueda de la seguridad a la organización política», Anuario de Estudios Indígenas VII, Instituto de Estudios Indígenas, Universidad Autónoma de Chiapas, México, pp. 283308.

Lan, Diana y Alejandro Migueltorena, 2011, «Formas de apropiación y espacios públicos en Tandil, a inicios del Siglo XXI», en Cuaderno Urbano. Espacio, Cultura, Sociedad, v. 10, n. 10. México, pp. 107-126.

Lindón, Alicia, 2004, «Las huellas de Lefebvre sobre la vida cotidiana», Veredas, n. 8, México, pp. 39-60.

Lindón, Alicia y Daniel Hiernaux, 2006, Tratado de geografia humana, Anthropos, Universidad Autónoma Metropolitana-Unidad Iztapalapa, México.

López Austin, Alfredo, 2001, «El núcleo duro», en Broda, Johanna y Baez-Jorge, Félix, Cosmovisión, ritual e identidad de los pueblos indígenas de México, UNAM, Coneculta, México. 
López, Daniel, 2005, «Aplicación de la teoría actor-red al análisis espacial de un servicio de teleasistencia domiciliaria», AIBR, Revista de antropología iberoamericana, n. 44, España, en http://www.aibr.org/antropologia/44nov/articulos/nov0508.php [consulta: 20 de febrero de 2012].

López, Liliana et al., 2006, «Fraccionamientos cerrados, mundos imaginarios», en Lindón, Alicia y otros (coords.), Lugares imaginarios en la metrópoli, Anthropos, UAM- Iztapalapa, México, pp. 161-169.

Lynch, Kevin, 1959, La imagen de la ciudad, Editorial Infinito, Buenos Aires.

Mançano Fernandes, Bernardo, 2006, «Movimientos socioterritoriales y movimientos socioespaciales. Contribución teórica para una lectura geográfica de los movimientos sociales», en http://geoestudiantes.weebly.com/bernardo-manccedilano.html [consulta: 19 de marzo de 2010].

Maņano Fernandes, Bernardo, 2008, «La ocupación como una forma de acceso a la tierra en Brasil: una contribución teórica y metodológica», en Moyo, Sam y Yeros, Paris, (coords.), Recuperando la tierra. El resurgimiento de movimientos rurales en África, Asia y América Latina, CLACSO, Buenos Aires, pp. 335-357, en http://biblioteca.clacso.edu.ar/ar/libros/sursur/moyo/ [consulta: 24 de febrero de 2013].

Martínez, Ricardo, 2011, «La ruta incierta en el tren de la muerte», Desinformémonos, $\mathrm{n}$. 11, México, en http://desinformemonos.org/2011/11/la-ruta-incierta-en-el-tren-de-lamuerte/print/ [consulta: 15 diciembre de 2012].

Palacios, Ana, 2010, «Representaciones sociales de la ciudad y la otredad», Revista Austral de Ciencias Sociales, n. 18, Buenos Aires, pp. 33-58. 
Pintos, Juan Luis, 2000, «Construyendo realidad(es): los imaginarios sociales», Universidad de Santiago de Compostela, España, en http://web.usc.es/ jlpintos/articulos/construyendo.htm [consulta: 25 de febrero de 2008].

Portal, Ana María, 2001 a, «Del centro histórico de Tlalpan al centro comercial Cuicuilco: la construcción de la multicentralidad urbana», en Aguilar, Miguel Ángel et al., La ciudad desde sus lugares. Trece ventanas etnográficas para una metrópoli, Porrúa, Conaculta, UAM-Iztapalapa, México, pp. 239-270.

Portal, Ana María, 2001b, Vivir la diversidad. Identidades y cultura en dos contextos urbanos de México, Conacyt, UAM-Iztapalapa, México.

Riera, Pedro, 2012, «Mundos vividos. La fenomenología de Merleau Ponty sobre el espacio mítico u onírico como paradigma de un pensar futuro que respete la diversidad», Revista Internacional de Filosofía, n. 3, pp. 189-197.

Ruiz, Verónica, 2007, «Ser mexicano en Chiapas. Identidad y ciudadanización entre los refugiados guatemaltecos en la Trinitaria, Chiapas», Tesis de Doctorado en Antropología Social, Ciesas, México.

Sánchez, Joan-Eugeni, 1991, Espacio, economía y sociedad, Siglo XXI, España, en http://www.ub.edu/geocrit/texap-6.pdf [consulta: 29 de agosto de 2012].

Spicer, Edward H., 1994, Los yaquis. Historia de una cultura, IIH UNAM, México.

Tello, Nelio, 2003, Cornelius Castoriadis y el imaginario radical, Campo de Ideas, Madrid. 
Telemadrid, 2008, http://www.youtube.com/watch?v=Q6TWnbEStYY [consulta: 10 de septiembre de 2012].

Tuan, Yi Fu, 2007, Topofilia. Un estudio sobre las percepciones, actitudes y valores scentlik, Editorial Melusina, España

Ultreras, Pedro, 2012, La bestia, la tragedia de migrantes centroamericanos en México, Secretaría de Desarrollo Rural y Equidad para las Comunidades, México.

Viqueira, Juan Pedro, 1994, «Regiones naturales, regiones nominales y regiones vividas», en http://cdigital.uv.mx/bitstream/123456789/8773/1/sotav3-Pag107-117.pdf [consulta: 1 de octubre de 2012].

\title{
NOTAS
}

\begin{abstract}
${ }^{1}$ Alfredo López Austin señala «Esa estructura o matriz de pensamiento y el conjunto de reguladores de las concepciones son lo que constituye el núcleo duro de la cosmovisión. Puede descubrirse, precisamente, entre las similitudes [...] En Mesoamérica la similitud profunda radicaba en un complejo articulado de elementos culturales, sumamente resistentes al cambio, que actuaban como estructurantes del acervo tradicional y permitían que los nuevos elementos se incorporaran a dicho acervo con un sentido congruente en el contexto cultural. Este complejo era el núcleo duro» (2001: 147-165).
\end{abstract}

Fecha de recepción: 7 de noviembre de 2012.

Fecha de aceptación: 18 de febrero de 2013. 